\title{
Research on Big Data Application in Precision Marketing
}

\author{
Xiaohong Qin ${ }^{1, ~ a ~ * a n d ~ J i n g f e n g ~ Z h a o ~}{ }^{1, b}$ \\ ${ }^{1}$ School of Economics and Management, Northwest University, 229 Taibai N. Rd. Xi'an, Shaanxi, \\ China 710069 \\ a34462423@qq.com, bhaojingfeng369@sina.com
}

Keywords: Big data; Precision marketing; Precision marketing mode; Delivered value theory

\begin{abstract}
Big data research and application has become a hot spot in the information technology field, but how to use big data research customer behavior characteristics, to establishment of the era of big data customer insight and precision marketing system, this area is very small. Based on the reviewed of big data and precision marketing, and Based on the general process of marketing, from customer information collection and processing, customer segmentation and positioning, marketing strategy development, marketing, design, marketing, feedback results in five areas to explore big data applications in Precision Marketing.
\end{abstract}

\section{Big Data Research Situation}

In 1980, the famous futurist Alvin Toffler in his "third wave" of the concept of "big data", but after a long period of time, due to the constraints of technological development, the concept of "big data" and not people attention [1]. Since 2008, mobile computing, networking, cloud computing and other emerging technologies have been a series of rise, the development of these technologies and social media, collaborative creation, virtual services and other new models in a wide range of applications, making the amount of data showing unprecedented global the explosive growth, the rapid growth of data complexity also requires new analytical methods and technologies to tap the value of data, big data technology came into being, and with the rapid development and application of an objective, and so, "big data" era truly arrived [2, 3, 4].

For the concept of big data, business and academia has not yet accepted the formation of precise definition. However, a common view is that the concept of big data and the "mass data" and "large-scale data," the same strain, but its data volume, data complexity and produce three speed are much beyond the traditional forms of data, but also beyond the technical means available processing power, and brings a huge industry innovation opportunities [5]. The characteristics of large data summarized into three "V": Volume, Velocity and Variety, but more people will be summed up as four "V", that is, volume, velocity, variety and value [6, 7].

At present, the research and application of data has become a hot spot in the field of information technology. Countries around the world attach great importance to research and exploration in the field of big data, and launch research programs from the national strategic level in order to meet the challenges it brings. Throughout the research and application development status at home and abroad in the field of big data visible: 1) Research and application-related big data is still in its infancy, academic research is mostly limited to the macro level; 2) large data based on the Internet and social media companies and application of the urgent need for further in-depth development; 3 ) the existing big data research mostly based on scientific information, focusing on large data acquisition, storage, processing, mining and other aspects of information security, few explore large from the perspective of management science for research data aspects of modern enterprise production management and business operations decisions brought about change and shocks [8,9]. 


\section{Precision Marketing Research Situation}

In 1999, Lester Wunderman proposed the concept of precision marketing. Zabin and Brebach proposed precision marketing rule 4R. Philip Kotler has described precision marketing, the first time into one of the Internet-based precision marketing theory, and that for marketing, it will communicate personalized, and at the right time for the right people to express and do the right thing, is crucial. etc. Paul. W. Farris and Neil. T. Bendle have research to solve the problem of marketing activities of the scientific quantification, precision marketing activities to help achieve good results .Lisa D Spiller and Martin Baier emphasizes that market segment for database-driven direct marketing basis. Achieve precision marketing in the Internet on the basis of complete direct marketing relationship between customers. Qi YB understood precision marketing is "accurate marketing", which contains the "standard" and "certain" two meanings. Wu Qingsheng et al. have proposed that precise marketing is through a combination of quantitative and qualitative methods to target market different consumers detailed analysis, based on their different consumer psychology and behavioral characteristics, enterprises to adopt targeted modern techniques, methods and point clear strategy to achieve the goal of a strong market effectiveness, high return on investment of marketing communication between different groups of consumers. Currently precision marketing research scholars enthusiasm quite high, a larger number of the relevant literature, but what is the precise marketing industry has not been given a universally accepted definition. Jiang He used to describe the precise marketing precision marketing. He believes that refinement of management with respect to extensive management terms, the face of meticulous management of marketing, customer segmentation means that based on one marketing strategy, that is, to the enterprise selected the most valuable customer base one on one, to understand individual needs and provide personalized channel personalized marketing tool. Cao caiJie also analyzed to: to network and information technology as the core of precision marketing system, to a certain extent replace traditional marketing methods, and gradually become a new trend of modern enterprise marketing development.

Taking these various viewpoints can be seen that the current precision marketing research scholars enthusiasm quite high, a larger number of the relevant literature, but what is the precise marketing industry has not been given a universally accepted definition. Precision marketing features are obvious: First, the accurate positioning of the market, the second is dependent on technological means, the third is personalized service, The four is to improve the accuracy of marketing. Although the precise definition of marketing is inconclusive, but that does not impede precision marketing ideas and methods of propagation. Since the popularity of the Internet, network marketing in the ascendant, Internet-based precision marketing is a hot field of network marketing and also the emergence of new research results. Precision Marketing will be widely promoted on the Internet in emerging industries, and gradually applied to traditional industries to go.

\section{Big Data Applications in Precision Marketing}

Marketing Management is combination art and science, which is select the target market, and through the creation, delivery and dissemination of high-quality customer value to gain customers, retain customers and improve customer science and art. Among, the establishment of "science" part of the data collection and analysis, and depends on a variety of marketing databases. Use of data throughout the entire marketing process in the whole story, for marketing effectiveness plays a crucial role in influence. Increasing emergence and development of a full range of big data, such as GPS positioning in general, to enable enterprises to understand and insight into the needs of the market is increasingly towards real-time and accurate technology, unprecedented opportunities for enterprises to achieve precision marketing [10,11].

Theoretical research results at home and abroad and large data precision marketing are many, but how to use big data and big data technology, research and customer behavior characteristics, the establishment of the era of large data precision marketing system and customer insight strategy, research in this area is very small. Science and technology in the use of marketing has always existed, 
but the use of big data in marketing is the combination of technology and marketing a new milestone, it enables technology marketing is icing on the cake is no longer just a tool, but rather to bring business marketing strategic transformation, play a revolutionary role. From the general process of marketing to analyze big data technology in Precision Marketing [12, 13].

Customer Information Gathering and Processing. Customer data management is a process of data preparation, data analysis and mining base, the key is to improve the precision marketing and infrastructure, which will cause the blind promotion, marketing and other excessive errors. For example, because some of the products purchased, there is a certain period of time will not repeat, forced recommended only lead to boredom and regret emotions. Traditional customer relationship management focus on two aspects of the general customer data: customer descriptive data and behavioral data. Descriptive data like a person's resume, such as name, gender, age, education and so on; behavior data is more complex, such as the number of consumers to purchase, purchase frequency, returns behavior, payment. In the era of big data, unstructured data accounts for only $15 \%$, more similar to the shopping process, social commentary, etc. Such non-structured data, and the data is very complex, in line $4 \mathrm{~V}$ features. Only through Big Data technologies to collect and collate data about the possible formation of a 360-degree customer database, yes, every marketing opportunity. "Beer and diapers," the marketing theory is a good example [14].

Customer Segmentation and Targeting. Only distinguish different customer base, companies may have to expand its diverse customer base and effective management and adopt different marketing tools, to provide to meet the requirements of the customer base characteristics of products or services. In practice, the traditional market segmentation variables such as demographic factors, geographic factors, psychological factors due only provide customers a more vague outline, has been difficult to provide a reliable basis for the accurate marketing decisions [15]. The era of big data, the use of Big Data technology in the mass rapid screening of unstructured information collected in the company valuable information on customer behavior patterns and accurately determine and analyze customer value, so that we may even understand "each people, "and not just" target population "to provide customer insight and marketing strategy [16].

Marketing Strategy Development. After obtaining the data based on the existing customer base of different characteristics, marketers need to combine corporate strategy, business, market conditions and other factors, looking for possible business opportunities in different groups of customers, and ultimately develop personalized marketing for each group strategy. Each marketing strategy has specific objectives. Such as access to similar customers, cross-sell or up-sell, or take measures to prevent the loss of customers and the like [17].

Marketing Program Design. Big Data era, a good marketing plan can be focused to a target audience, or even precisely according to each consumer's interests and preferences to provide different marketing mix programs specifically targeted property portfolio includes solutions for them, product price plan, channel design, one to one communication marketing programs. Information such as $\mathrm{O} 2 \mathrm{O}$ channel design, online advertising audience buying and real-time bidding technology, location-based promotions [18].

Marketing Results Back. Big Data era, the end of the campaign, during the execution of marketing activities to respond to a variety of data collected comprehensive analysis, to explore the data from the mass market in the most efficient enterprise performance metrics, and the traditional market performance metrics companies to start comparison to establish new metrics based on the data of superiority and value to the effectiveness of marketing campaigns executed, channels, products and advertising to assess, lay a good foundation for the next phase of the campaign [19].

\section{Conclusion}

Big data will be the next innovation in a world, competition and productivity frontier. Marketing is essentially a more efficient process, and technology is helping this process of transformation. Big data to improve efficiency, precision marketing has much to offer, it is helping companies understand 
"everyone" rather than a "target population," it really to allow customers to become "chief executive customer", trying to create for each customer the "Keys" system. This promotion of business efficiency, but also give consumers new private customized experience to increase consumer welfare. From the general process of marketing the technology in large data precision marketing in order to provide a reference precision marketing enterprises.

\section{Acknowledgements}

This research was financially supported by the Research of Shaanxi Provincial Department of Education special research project (15JK2176).

\section{References}

[1] Bo research. Big Data era of precision marketing model. [J]. Economist, 2013 (5).

[2] See any broad based business model of Big Data Innovation and Enlightenment [J]. Modern Business Trade Industry, 2013 (20).

[3] Gu Lijun, Xu Xin. On the Nature and Marketing Implications of "big data" [J]. Social Sciences, 2013 (7).

[4] Pingzhi Yan, Guo Hua Xun, who the army, Chen Yubo, Chen Guoqing. Business management research topics at the forefront of several large data background [J]. Journal of Management Science, 2013 (1).

[5] Liwen Lian, Xia Jianming Innovation [J] based on the "big data" business model. China Industrial Economy, 2013 (5).

[6] Lynch C.Big data: How do your data grow[J].Nature,2008,455( 7209) : 28-29.

[7] Hilbert M, Lopez P. The world's technological capacity to store, communicate, and compute information [J].Science, 2011, 332(6025): 60-65.

[8] Bughin J,Chui M,Manyika J. Clouds, big data,and smart assets: Ten tech-enabled business trends to watch[J]. McKinsey Quarterly, 2010( 8): 1-14.

[9] Anderson C. The end of theory: The data deluge makes the scientific method obsolete [J] Wired Magazine,2008,16( 7) :1-3.

[10] Frankel F, Reid R. Big data: Distilling meaning from data [J]. Nature,2008,455( 7209) : 30.

[11] Lavalle S, Lesser E, Shockley R, et al. Big data, analytics and the path from insights to value [J]. MIT Sloan Management Review, 2011.

[12] Manyika J, Chui M, Brown B, et al. Big Data: The Next Frontier for Innovation, Competition, and Productivity [M]. New York: McKinsey Company,2011.

[13] Hui SK, Fader PS, Path data in marketing: An integrative framework and prospectus for model building [J]. Marketing Science,2009,28:320-335.

[14] Borgatti SP, Mehra A， Brass D J, et al. Network analysis in the social sciences[J]. Science, 2009, 892-895.

[15] Ghose A,HanSP. An empirical analysis of user content generation and usage behavior on the mobile internet [J]. Management Science,2011,57( 9) : 1671-1691.

[16] Ghose A,HanSP. An empirical analysis of user content generation and usage behavior on the mobile internet [J]. Management Science,2011,57( 9) : 1671-1691.

[17] Ghose A, IpeirotisPG. Designing ranking systems for hotels on travel search engines by mining user-generated and crowdsourced content [J]. Marketing Science. 2012, 493- 520. 
[18] AralS, WalkeD. Creating social contagion through viral product design: A randomized trial of peer influence in networks[J].Management Science,2011,57( 9) : 1623-1639.

[19] Archak N, Ghose A, Ipeirotis PG. Deriving the pricing power of product features by mining consumer reviews [J]. Management Science,2011,57( 8): 1485-1509. 